\title{
TOWARDS GREEN RATING SYSTEMS IN HUNGARIAN ROAD DESIGN
}

\author{
${ }^{1}$ Réka NÁDASI ${ }^{*}$ Csaba TÓTH \\ ${ }^{1,2}$ Department of Highway and Railway Engineering, Budapest University of Technology and \\ Economics, 1111 Budapest, Müegyetem rkp. 3, Hungary \\ email: ${ }^{1}$ nadasi.reka@epito.bme.hu, ${ }^{2}$ toth.csaba@epito.bme.hu
}

Received 30 December 2017; accepted 7 November 2018

\begin{abstract}
To measure the environmental impacts, life cycle assessment techniques appeared. The paper presents the SimaPro, which is one of the most widely, used software for life cycle assessment. Studies indicate that environmental impact can be considerably reduced in the planning and the design stages, if sustainability is evaluated. Therefore, a system of objective measurement is inevitable. Nowadays, numerous road rating systems exist and are used around the World. Taking into consideration EU directives, employing a rating system in Hungary has great importance. Therefore, paper presents an action plan to develop a domestic sustainable evaluation tool for road construction.
\end{abstract}

Keywords: Sustainability, Life cycle assessment, Rating systems

\section{Introduction}

Sustainability increasingly becomes a concern to society and becomes a major challenge in the entire world. Professions have a rising awareness that certain human activities are generating harmful effect to our environment and the planet's well-being. As it can threaten the existence of future generations, it is important to develop sustainable technologies to reduce these noxious effects. After energy production, the most notably impact on Green House Gas (GHG) emission is generated by burning fossil fuels for transportation [1]. It is also well known, that the GHG emission is one of the main issues for the climate change. Among others, this is the reason for rising sea

\footnotetext{
${ }^{*}$ Corresponding Author
} 
levels, shrinking glaciers, water scarcity, change in the range and distribution of plants and animals, and seasonal irregularities.

In the case of transportation, it is important to find the way how to make the network and operations sustainable. Although it is known that sustainability is a necessary economic and social development aimed at protecting the environment, however, there is still no solid approach to sustainability, as well as a single definition cannot cover all the concepts and processes of sustainability. Therefore, different methods and tools were developed to evaluate and rate the sustainability performance of an infrastructure project. For instance, Cost-Benefit Analysis (CBA), Life Cycle Cost Assessment (LCCA), Life Cycle Assessment (LCA), Environmental Impact Assessment (EIA) and Green Road Rating Systems (GRRS) [2]. This paper focuses of the LCA method and the rating systems.

Numerous LCA methods and software were developed during the years to show the greatness and importance of the impacts in each stage of road constructions. This paper introduces the SimaPro program, which is one of the most widely used software for LCA studies.

To measure the success of sustainability and help the decision makers, a system of objective measurement is inevitable. In the example of well-known and worldwidespared used green rating systems for buildings, e.g. Leadership in Energy and Environmental Design (LEED), it has also vast significance to introduce it to the infrastructure sector. Nowadays, several rating systems exist like Greenroads, GreenLITES, I-LAST, Invest or the Envision. This paper emphasizes the importance and introduce the flow chart of the invention of a framework of a Hungarian sustainability-based rating system.

\section{Life cycle assessment}

The aim of the paper is to highlight the importance of sustainability of road constructions. According to [3], the requirements for sustainable road pavement construction are the followings:

- Design for long-life pavements;

- Promote resource efficiency by adopting quality paving materials and innovative maintenance techniques;

- Increase re-use and recycling in road works;

- Entire life cost analysis;

- Address the life-time rather than short-term costs;

- Implement an effective Environmental Management System (EMS);

- Reduce site emissions, pollution and waste volume, reduce water and energy use;

- Health and safety;

- Responsible procurement, selling and marketing.

With the spreading use of sustainability in pavement, highway and urban planning [4], the life-cycle thinking is also coming into the focus. It means all the series of stages 
and changes through which it passes during its lifetime. The impact of roads and highways on the environment is significant resulting from its life cycle activities, which involve planning, design, material extraction, construction, usage, maintenance and demolition (Fig. 1). With LCA analysis, it is possible to predict road's impacts during the entire life cycle. For this reason, this method becomes important before the construction itself.

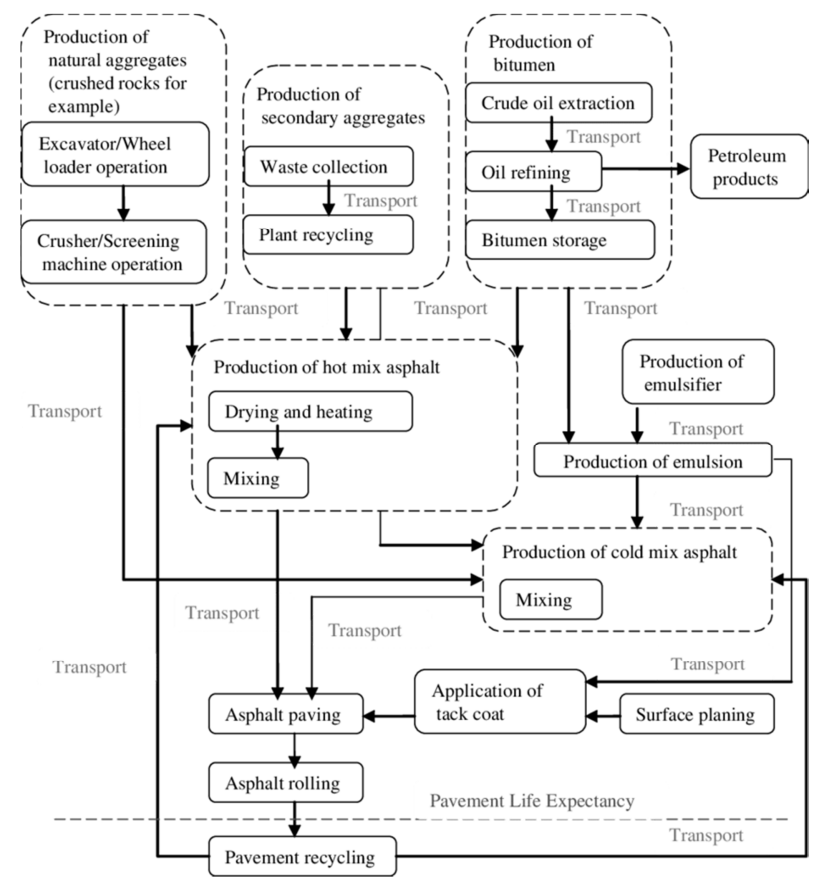

Fig. 1. Asphalt pavement lifecycle process [5]

The ISO 14040 standard describes the principles and the framework of LCA [6]. According to this, life cycle assessment is a technique for estimate the potential environmental aspects of a product or service, by taking inventory of the relevant data, evaluating the impacts and analyzes the results [7]. However, there are several LCA studies in road construction [5], [8]-[10], in the case of infrastructure facilities, there is no integrated LCA methodology. LCA is generally limited to materials, construction vehicles and engine alternatives. It is also important, that modules like 'usage' and 'endof-life processes' have received less attention in the studies.

\subsection{SimaPro}

SimaPro is one of the world most widely used Life Cycle Assessment software for business and education. The program provides a professional tool to collect, analyze and monitor the sustainability performance of products to help the sustainable decision makers. The usage of the software is flexible and easy to use. It is a great tool for the 
companies and researchers to analyze the environmental impacts of any object, system or service. Many different impact assessment methods are available in the software with large amount of data [11]. The software also includes the Ecoinvent database. Ecoinvent is the world most consistent and transparent life cycle inventory database, which provides well-documented process data for thousands of products.

When all data is available from Fig. 1, thereby the inventory is done, the next step is to add these to the program and build the model. In the program, numerous methods are available to analyze the system or service. Examiners can scrutinize the entire network, or any part of that. Different impact assessment methods are available in the software and many tutorials accessible on the internet. Examiners can choose the methods, which best fit to the project, as different European methods, North American methods, water footprint and single issue (e.g. cumulative energy demand, ecosystem demand potential, greenhouse gas protocol). The most frequently used method is presumably the European ReCiPe, which in case of midpoint analysis includes 18 impact categories, like:

1. Ozone depletion;

2. Human toxicity;

3. Ionizing radiation;

4. Photochemical oxidant formation;

5. Particulate matter formation;

6. Terrestrial acidification;

7. Climate change;

8. Terrestrial ecotoxicity;

9. Agricultural land occupation;
10. Urban land occupation;

11. Natural land transformation;

12. Marine ecotoxicity;

13. Marine eutrophication;

14. Fresh water eutrophication;

15. Fresh water ecotoxicity;

16. Fossil fuel depletion;

17. Minerals depletion;

18. Fresh water depletion.

At the endpoint level, most of these midpoint impact categories are multiplied by damage factors and aggregated into three endpoint categories. Those categories are human health, ecosystems and resource surplus costs [11]. The assessment is also available for the entire or any section of the network for all the categories or only one of them.

Next to characterization, normalization and weighting are also available in the program for the assessment of the outcomes. Generally, normalization and weighting are used to simplify the interpretation of the results. With normalization the results can be placed in a broader context and give common dimensions. Typically, the formula

$$
N_{i}=\frac{I_{i}}{R_{i}}
$$

helps to reach that, where $N$ is the normalized result, $I$ is the result from the characterization and $R$ is a reference value. Weighting is the process to convert indicator results by using numerical factors based on value choices; it may include aggregation across impact categories.

Fig. 2 presents the outlook of a network - in this case a concrete pavement 20 years $L C A$ with the respect of climate change. The thickness of the arrows shows the most influential steps of the network. All the data can be illustrated with graphs or listed in tables, which then can be easily exported to other software e.g. Excel or a pdf file. 


\subsection{Results with SimaPro}

In the Master Thesis [12] the Author had the opportunity to get acquainted with the LCA method. Although the focus was on the comparison of electrified roads I also looked at the effect of the traditional pavement as a comparison basis with SimaPro. The Functional Unit (FU) was a 10,000 $\mathrm{m}$ long $3.5 \mathrm{~m}$ wide asphalt pavement motorway lane section with the layer-thicknesses of $4 \mathrm{~cm}$ (SMA11), $9 \mathrm{~cm}$ (AC22) and $10 \mathrm{~cm}$ (AC22). This non-real section was located in Sweden.

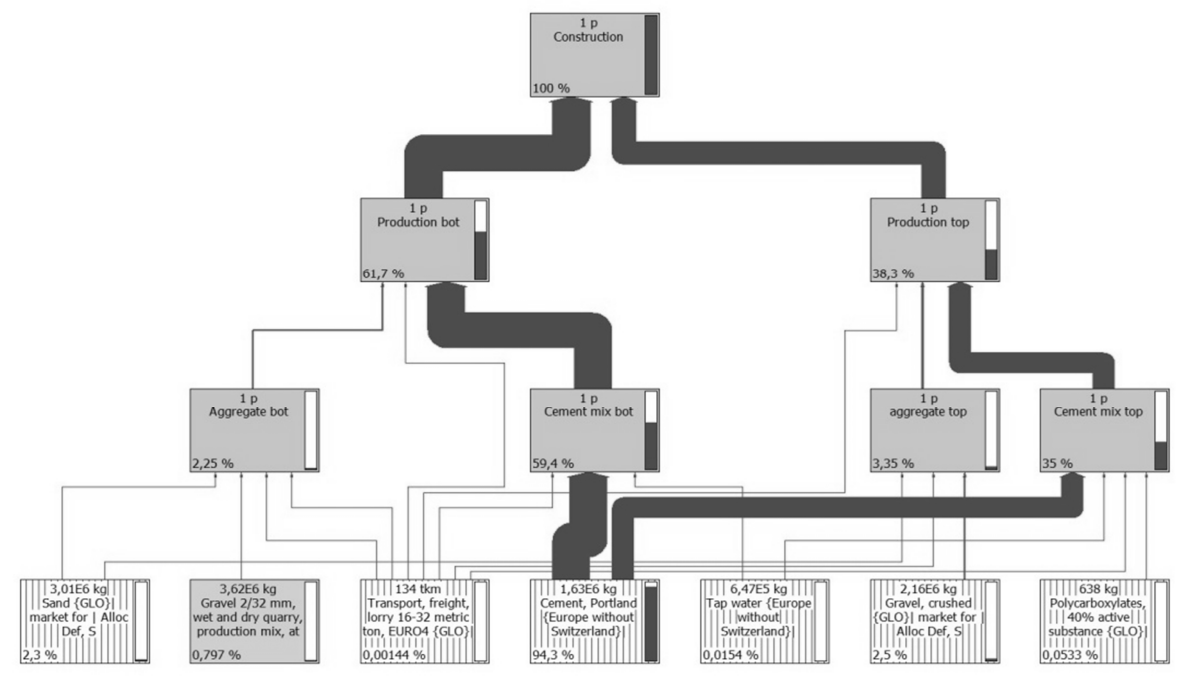

Fig. 2. SimaPro network surface

For the systematic application of the software, all the values need to be given in $\mathrm{kg}$ and $\mathrm{m}^{3}$ units. Based on the known volumes and the asphalt mixture plan, the demand for certain quantities of raw materials per layer - in terms of their density - can easily be calculated in $[\mathrm{kg}]$. As it is shown in the simplified flowchart (Fig. 3), the analysis of the transport of certain items (raw material, asphalt mixture) is also important. The model calculates with the average transport of raw materials from $50 \mathrm{~km}$, and the mixing plant is $30 \mathrm{~km}$ from the construction site.

For the determination and simulation of the asphalt mixing process, the Ecoinvent database was used with slight modifications. In the case of the transport of materials and asphalt mixtures, the model calculates with trucks with a size of 32 tons and EURO III type. Since, it is also available from the program's database, only the necessary km of transport is required. The next step is the installation process. As the study focuses on climate change, the model - based on the research of Stripple [13] - calculates the diesel fuel consumption of construction machines. Because of the size limitations of the paper, the exact steps of the calculation are not introduced here. The result of the diesel consumption is: asphalt paver - $2550 \mathrm{~kg}$; road roller - $1567 \mathrm{~kg}$, bitumen sprayer $76.5 \mathrm{~kg}$. 
The next stage of lifecycle of the road is the 'use phase'. The model does not count on the effects of traffic; therefore, the output and raw material needs here are coming from the maintenance and operational material needs. The amount of this is very significant during the 20 years of the road service life.

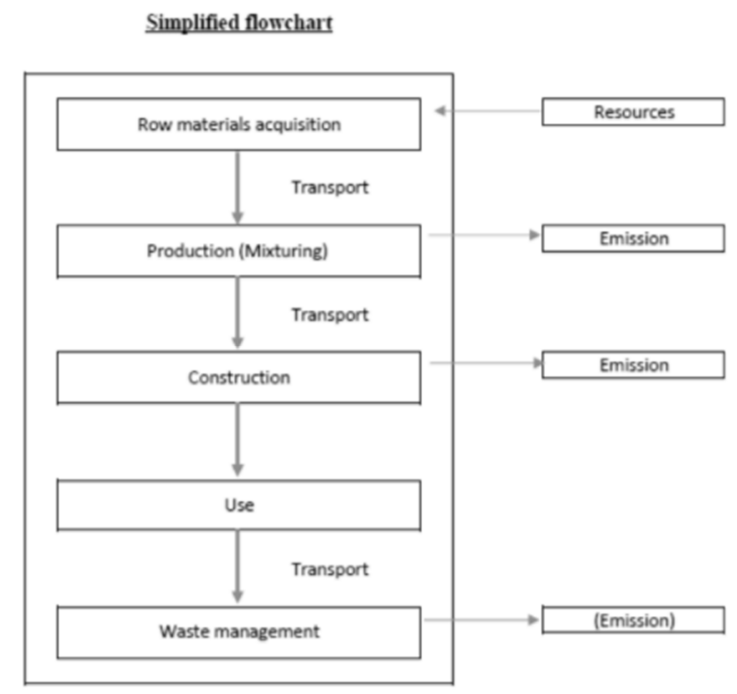

Fig. 3. Simplified flowchart of process

After the model has built, the sections can be analysed using a several methods. In this case, a ReCiPe Midpoint $(\mathrm{H})$ impact assessment method was applied. The normalized (without units) results are visible in Fig. 4 - Fig. 5. This result can be further analysed either from inventory analysis or from the perspective of process inputs both in the case of the entire phase, or only different sub-tasks.

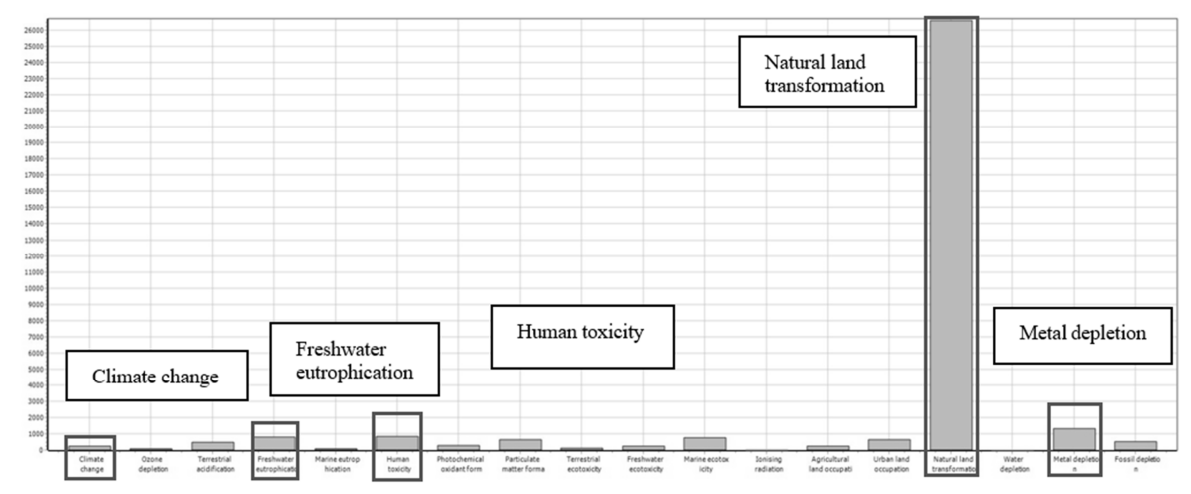

Fig. 4. The result of impact assessment

Pollack Periodica 14, 2019, 2 
The results of the impact assessment show that the highest value belongs to the natural land transformation. This is understandable because a substantial amount of raw material is needed for the construction and maintenance of a $10 \mathrm{~km}$ section and the roadway. This is followed by metal depletion, human toxicity, and freshwater eutrophication. Contrary to climate change has significantly lower values than the other factors, for assessing sustainability; its impact is not negligible.

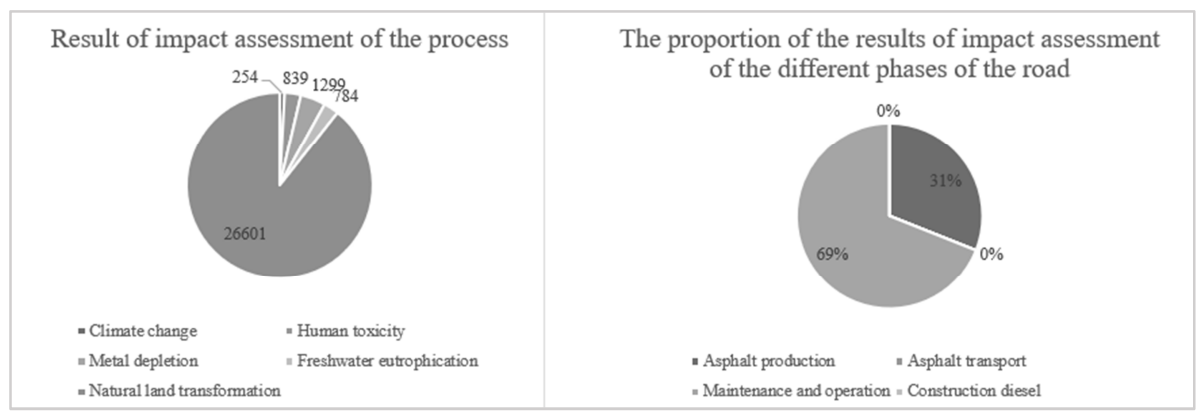

Fig. 5. a) The distribution of result of impact assessment, b) Impact assessment results of the different phases of the road life-cycle

The results of the impact assessment show that, (Fig. 5b), the most significant effect of the road segment during the 20 years of service life is the maintenance and operation work $(69 \%)$. It is followed by the process of asphalt production $(31 \%)$, which includes the raw material requirement and the mixing process. In addition to these values, the fuel requirement for construction and the delivery of asphalt mixtures to the site are negligible over the 20 years period.

However, this work gave me a great overview about the usage of SimaPro and processes of LCA modeling in road construction, the model could have been further improved with deeper data collection and with considering data uncertainties.

\section{The importance of the objective rating systems}

Next to the advantages of LCA analysis, there are also drawbacks of this method. For instance, the data uncertainty and the necessary limitations can make significant changes in the final result [14]. In addition, studies are specified for only one particular project and usually cause high extra-costs, moreover, building and analyzing the model is time consuming. For this reason, the development of an objective and widely useable rating system is necessary. These rating systems could be used for each project and it makes opportunities to compare them with each other in environmental and sustainable aspects helping the stakeholders and decision makers. This approach is also important since studies [15]-[18] indicate that the environmental impact can be considerably reduced in the planning and the design stages if sustainability is evaluated.

It is generally accepted, that the incorporation of sustainability in roadway design has difficulties, barriers and limitations. It can cause additional fees, additional 
complications and extra men-hour spending. The study of [16] pointed to the problem of the average difficulties of 'green' road design. The authors compared 14 elements both for materials and techniques difficulties. According to this research the natural preconditions, criteria and specifications, owner policy and law and the lack of experiences have the highest influences.

Therefore, to support the application of well-designed policy and law, objective rating systems has an important role.

\subsection{Rating systems}

The first efforts to establish an objective rating system for construction started with the LEED, or Leadership in Energy and Environmental Design in 2000. It provides a framework to create healthy, highly efficient and cost-saving green buildings, as it provides a checklist of prerequisites and credits to evaluate the environmental performance of buildings [19]. Next to the building constructions, transportation facilities also imply significant $\mathrm{CO}_{2}$ emission. Therefore, applying this approach to road construction is unavoidable. Nowadays, many systems are available. Generally, all the rating systems have the same aim, which is to shift the market from substandard performance and typical construction practices to the green market leaders and green road innovators with the support of different green practices and activities [20-25].

This paper is focusing on the GreenRoads, GreenLITES, I-LAST, Envision and INVEST rating systems. They had been developed in the US and/or Canada by universities, infrastructure institutes and administrations. Generally, it can be stated, that all the examined systems are rating the projects based on their sustainable performance during the different levels of the projects i.e. system development, project development, operation and maintenance. For this, a checklist with different categories and credits with different weights and maximum points are used. From the five analyzed systems, the I-LAST is the only one which gives no certification. The aim of the I-LAST is the usage of the collected green methods and activities and evaluates the performance-level of them in the infrastructure projects. Most of the rating systems use the same worksheet for all the projects, but the INVEST. This system distinguishes the projects based on its location (rural/urban) and type (reconstruction/new road construction).

The number of listed credits and the maximum available points are also wildly different (61-175 credits, 130-1000 points), but all the systems require a minimum point for the certification $(5-30 \%)$. The result of the project can be used for educational purposes, labeling and different marketing goals, as well as to help the decision making.

Based on the manuals and the studies [20]-[26], most of the system-credits can be classified into the following categories: Material \& Pavement technology, Environmental \& Water, Design \& Construction, Access \& Equality and Energy Efficiency. However, the different systems consider different areas as 'most important', giving them the most obtainable credits and points. It also needs to be remarked, that the Greenroads rating system next to the minimum acquired point limit, requires 12 mandatory credits for the certification. In this 'Project Requirements', important credits like Ecological Impact Analysis, Energy \& Carbon Footprint, Lifecycle Cost Analysis, Pollution Prevention, Waste Management and Noise \& Glare Control can be found. 
All the examined rating system has been used for several projects around the World, what proved the accuracy and importance of them. However, due to climate and landscape differences as well as the disparity of local demands e.g. social and investor demand, some countries (Australia, South-Korea, India, Taiwan etc.) decided to develop an own rating system what befit these needs.

\subsection{The development and application of rating system in Hungary}

Acknowledging the importance of sustainable practices and activities, these or similar rating systems are used both in developed and developing countries around the world (e.g. USA, Australia, New-Zealand, Republic of South Africa, Iran, Israel, Taiwan, Malaysia, or South Korea).

Based on the beyond mentioned own rating systems, this paper is intended to show the importance and the processes of establishing such a system in Hungary for the reason to promote the sustainable development and to catch up with major European countries.

Therefore, the authors' next plan is to determine the system, which can fit the best to the Hungarian practice. With the support of this rating system the certification of a currently running project can be done and from the results, the advantages and disadvantages of the Hungarian road construction practice can be assessed.

The action plan is visible in Fig. 6, what based on the example of South-Korea, Taiwan and the research of Colorado State University [27]. The separation between step III and IV refers the planned boundary of the research. Therefore, the aim is to develop the framework of the Hungarian rating system.

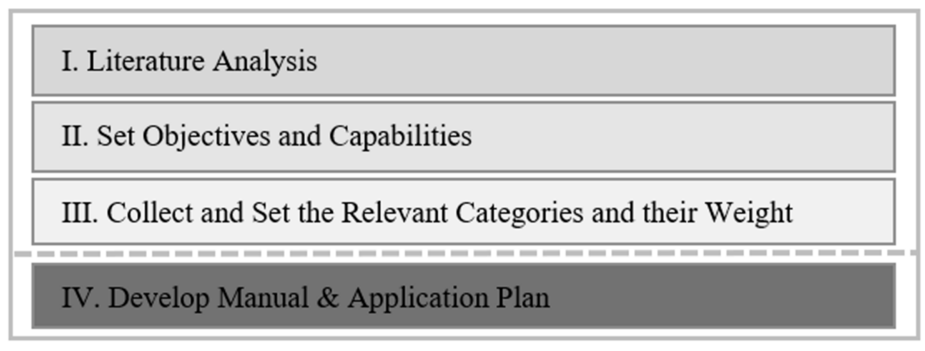

Fig. 6. Planned action plan for developing a Hungarian rating system

The different steps of the action plan of developing a Hungarian rating system are:

1. Literature analysis;

Analysis of sustainable methods and activities, different rating systems and their categories, credits and weights,

2. Set objectives and capabilities;

Determination of the application boundary (project phases, project types) and application methods e.g.: 
Feasibility of self-assessment; Ability to choose only relevant criteria to project; Ability to offer different checklist for different types of projects; Award points for innovation; Capability to compare different project options;

3. Collect and set the relevant categories and their weight;

Develop the framework of a competent and coherent rating system based on the objectives what fit the Hungarian practices with conducting interviews with industry experts;

4. Develop manual \& application plan;

The aim of the manual is to give a clear overall view of the applied sustainable tools and activities, describe their application in the project and explain the allocation of the acquired points. (The ability of the usage of the manual in education can give a significant role). Finally, set the application plan has importance for the operation.

As Fig. 7 shows, the research is aimed to be finished at 2021. It is also visible, that the study is in the II. phase, where the objectives needs to be set. For this literature review interviews and questionnaire will be used.

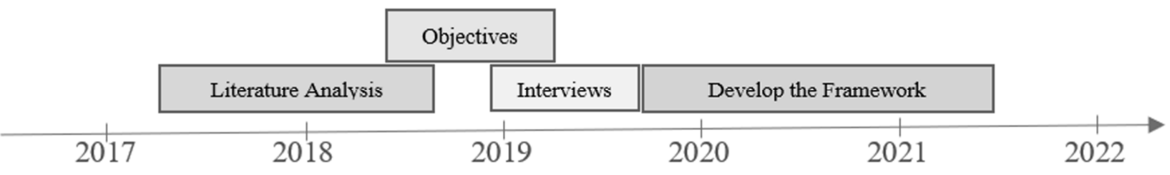

Fig. 7. Aimed action plan for developing a Hungarian rating system

The goal of the interviews of industry experts is to obtain an overall view about the current level of sustainability in the different phases of the project and to detect the required enhancements and changes. The analysis of the interviews is planned to be made by Analytic Hierarchy Process (AHP). With this, the collection and finalization of the categories aimed to be done. Moreover, the interview will contain both open-ended and closed-ended questions and will give opportunity to signify the concerns that may influence the results of the research.

After the adequate amount and depth of research and interviews, with the analysis and evaluation of the answers, the framework of the Hungarian rating system can be developed as the main goal of the research.

\section{Conclusion}

This paper is intended to present importance of sustainable assessment tools, like LCA and objective 'green' rating systems for road and pavement design. First, the paper describes the steps of LCA studies and presents usage of the SimaPro software with a general example of an asphalt pavement. As all the evaluation tools in general, as well as the LCA studies have drawbacks, the paper reflects the benefit of the usage of the different sustainable based rating systems. The purpose of these systems is to use the desirable sustainable practices and rate the level of their application during the different 
level of project phases. The paper shortly introduces five widely used rating systems for infrastructure projects, namely: Greenroads, GreenLITES, I-LAST, Envision and INVEST. These systems rate and/or certificate the projects based on their achieved points. The result of the project can be used for educational purposes, labeling and different marketing goals, as well as to help the decision making.

The general aim of the paper is to highlight the importance of the application of green rating systems in Hungarian road and pavement design. For this, an action plan is introduced to show the process of this research.

\section{Open Access statement}

This is an open-access article distributed under the terms of the Creative Commons Attribution 4.0 International License (https://creativecommons.org/licenses/by/4.0/), which permits unrestricted use, distribution, and reproduction in any medium, provided the original author and source are credited, a link to the $\mathrm{CC}$ License is provided, and changes - if any - are indicated. (SID_1)

\section{References}

[1] Török Á., Zoldy M. Energetic and economical investigation of greenhouse gas emission of Hungarian road transport sector, Pollack Periodica, Vol. 5, No. 3, 2010, pp. 123-132.

[2] Gopalakrishnan K. Sustainable highways, pavements and materials, An introduction, Transdependenz LLC, 2011.

[3] Parry A. R. A model set of asphalt sustainability indicators, The Future of Transport, 2005, pp. 1-10.

[4] Portschy S. Community participation in sustainable urban growth, case study of Almere, The Netherlands, Pollack Periodica, Vol. 11, No. 1, 2016, pp. 145-155.

[5] Huang Y., Heidrich O., Bird R. Development of a life cycle assessment tool for construction and maintenance of asphalt pavements, Journal of Cleaner Production, Vol. 17, No. 2, 2009, pp 283-296.

[6] ISO 14040:2006, Environmental management - Life cycle assessment - Principles and framework, 2006.

[7] Wolf M. A., Pant R., Chomkhamsri K., Sala S., Pennington D. The international reference life cycle data system (ILCD) Handbook, Joint Research Center Reference Reports, European Comission, 2010.

[8] Treloar G. J., Love P. E. D., Crawford R. H. Hybrid life-cycle inventory for road construction and use, J. Constr. Eng. Manag, Vol. 130, No. 1, 2004, pp. 43-49.

[9] Yu B., Lu Q., Xu J. An improved pavement maintenance optimization methodology: Integrating LCA and LCCA, Transp. Res. Part A, Policy and Practice, Vol. 55, 2013, pp. $1-11$.

[10] Santero N. J., Masanet E., Horvath A. Life-cycle assessment of pavements, Part I: Critical review, Resour. Conserv. Recycl. Vol. 55, No. 9-10, 2011, pp. 801-809.

[11] PRé, SimaPro Database Manual - Methods Library, C 2002-2016 PRé, San Francisco, 2016.

[12] Nádasi R. Life cycle assessment development for electrified roads: Case study for Sweden, Master Thesis, Stockholm, Sweden, 2017. 
[13] Stripple H. Life cycle assessment of road - A pilot study for inventory analysis, Research report, Gothenburg, Sweden, 2001.

[14] AzariJafari H., Yahia A., Amor B. Assessing the individual and combined effects of uncertainty and variability sources in comparative LCA of pavements, The International Journal of Life Cycle, Vol. 23, No. 9, 2018, pp. 1888-1902.

[15] Chang A. S., Tsai C. Y. Sustainable design indicators: Roadway project as an example, Ecological Indicators, Vol. 53, 2015, p. 137-143.

[16] Chang A. S., Tsaia C. Y. Difficulty and reasons for sustainable roadway design - the case from Taiwan, Journal of Civil Engineering and Management, Vol. 21, No. 4, 2015, pp. 395-406.

[17] McLellan B. C., G. D., Giurco D., Green S. Incorporating sustainable development in the design of mineral processing operations, Review and analysis of current approaches, Journal of Cleaner Production, Vol. 17, No. 16, 2009, pp. 1414-1425.

[18] Douven W., Buurman J. Planning practice in support of economically and environmentally sustainable roads in floodplains: the case of the Mekong delta floodplains, Journal of Environmental Management, Vol. 128, 2013, p. 161-168.

[19] LEED, U. S. Green Building Council, 2017, https://new.usgbc.org/leed, (last visited 20 Novembere 2017).

[20] Muench S. T., Anderson J., Bevan T. Greenroads: Development of a sustainability rating system for roadways, Int. J. Pavement Res. Technol, Vol. 3, No. 5, 2010, pp. 270-279. TRB 2009 Annual Meeting, 2009.

[21] The Greenroads Rating System, 2017, https://www.greenroads.org/files/8646.pdf. (last visited 1 December 2017).

[22] GreenLITES, https://www.dot.ny.gov/programs/greenlites, 2017, (last visited 1 December 2017).

[23] Kazmierowski T., Navarra M. Sustainability metrics of two pavement rating systems developed in Canada, Conference on the Green Technologies, Session: Innovation to Implementation and Evaluation, Transportation Association of Canada, Montreal, Quebec, 2014, pp. 1-17.

[24] Envision facts, 2014. https://www.asce.org/uploadedFiles/Issues_and_Advocacy/ Our_Initiatives/Sustainability/Content_Pieces/envision-fact-sheet.pdf, (last visited 5 December 2017).

[25] Lee J., Edil T. B., Benson C. H., Tinjum J. M. Building environmentally and economically sustainable transportation infrastructure: Green highway rating system, Journal of Construction Engineering and Management, Vol. 139, No. 12, 2013, pp. A4013006 1-10.

[26] Bujang M., Hainin M. R., Yadollahi M., Majid M. Z. A., Zin R. M., Azahar W. N. A. W. Pavement material and technology elements in green highway rating systems, A conspectus, Jurnal Teknologi, Vol. 70, No. 7, 2014, pp. 131-138.

[27] Simpson S. P., Ozbek M. E., Clevenger C. M., Atadero R. A. A framework for assessing transportation sustainability rating systems for implementation in U.S, Research Report, State Departments of Transportation, 2014. 